\title{
The Use of Borax in Deterring Flash Setting of High Calcium Fly Ash Based Geopolymer
}

\section{Antoni $^{1,2, a}$, Stephen Wibiatma Wijaya ${ }^{1, b}$, Juan Satria ${ }^{1, c}$, Agung Sugiarto ${ }^{1, d}$ and Djwantoro Hardjito ${ }^{1,2, e}$}

\author{
${ }^{1}$ Department of Civil Engineering, Petra Christian University, Indonesia \\ ${ }^{2}$ Center of Excellence Geopolymer \& Green Technology (CEGeoGTech), School of Materials \\ Engineering, Universiti Malaysia Perlis, Malaysia \\ aantoni@petra.ac.id, bstephen.wibi@yahoo.com, cjuansatria94@gmail.com, \\ dagung_91101@yahoo.com, edjwantoro.h@petra.ac.id
}

Keywords: flash setting, borax, geopolymer, high calcium, fly ash, admixture

\begin{abstract}
Geopolymer that was made with high $\mathrm{CaO}$ content fly ash was found to have higher compressive strength than the low $\mathrm{CaO}$ fly ash, using the same mixture composition. This effect could be due to the physico-chemical properties of the fly ash, in respect to its particle size or the chemical composition. Although it was not widely published, the occurrence of flash setting of geopolymer was known to occur when using high $\mathrm{CaO}$ content fly ash as the precursor. Geopolymer paste may solidify within minutes after the addition of alkali activators, making it very difficult to cast in big volume. This paper investigate the effect of borax addition to the high calcium fly ash-based geopolymer mixture to reduce the occurrence of flash setting. It was found that the setting time can be extended significantly, with the addition of $5 \%$ borax, by mass, of fly ash. The addition of borax also have positive effect on increasing the compressive strength of geopolymer.
\end{abstract}

\section{Introduction}

In recent years, the use of high calcium fly ash as cement replacement have been investigated widely. Fly ash possesses beneficial properties, i.e. it can undergo hydration and pozzolanic reaction in the Portland cement matrix. The use of only high calcium fly ash, without any Portland cement, can produce concrete with strength of $33 \mathrm{MPa}$ at 28 days, with the addition of water [1].

Variation of fly ash quality, such as the chemical composition, is directly related to the variation of the coal itself, as the combustion source. This causes concern on the reliability of the final product, when large portion of fly ash is used to make concrete [2]. Rapid method to detect the variation of fly ash has been suggested by the authors by measuring its $\mathrm{pH}$ level in aqueous solution, as an indicator of the $\mathrm{CaO}$ content in fly ash [3].

High calcium fly ash has been used as precursor for making geopolymer by several researchers [4-7]. In their studies, fly ash with $\mathrm{CaO}$ content ranging from $15-20 \%$, by mass, was used to produce geopolymer with compressive strength of 50 to $65 \mathrm{MPa}$. Faster setting time was reported when compared with the low calcium fly ash-based geopolymer [8]. Under normal curing condition, setting time of 28 to 68 minutes was reported [6].

The phenomenon of flash or rapid setting, defined as rapid hardening of geopolymer mixture of only several minutes after the addition of alkaline activator, has rarely been reported. Several authors mentioned the occurrence of flash setting when making geopolymer [9-11], however the phenomenon has not yet been investigated thoroughly. Davidovits stated that fly ash with higher $\mathrm{pH}$ level tends to have higher $\mathrm{CaO}$ content, and also to cause higher possibility of flash setting occurrence [12]. Rapid setting of geopolymer can cause problem when casting large volume geopolymer, and hence longer setting time should be ensured.

The use of additive to prolong the setting time and to increase the workability of geopolymer mixture has been suggested by several authors. Naphthalene based superplasticizer [4], dipotassium phosphate [11] and sucrose [13] have been mixed in the geopolymer mixture to slow down the 
polymerization reaction rate. However, reduction of strength was observed on the final geopolymer product, showing that they have detrimental effect.

Borax as retarding additive was not well known to be used in Portland cement or geopolymer, but several researchers have mentioned that it could be used to retard the setting time of concrete $[1,9]$. Using $100 \%$ high calcium fly ash as cement paste, Cross et al. [1] encountered flash setting. It could be reduced with borax addition of $1.25 \%$, by mass of fly ash. The use of borax in geopolymer mixture with the aim to increase the compressive strength has been reported by Tailby and MacKenzie [9]. The addition of borax of $10 \%$ by mass of fly ash increased the compressive strength of geopolymer when compared to those without borax. The use of borax to replace sodium silicate as the alkaline activator was reported by Nazari et al. [14]. Borax was used together with $\mathrm{NaOH}$ solution for the alkaline activator, whereas the use of borax was about $35 \%$, by mass, of fly ash. It was reported that the use of borax in the geopolymer mixture resulted in favorable effect.

The objectives of this paper are to report the occurrence of flash setting in the geopolymer mixture when using high calcium fly ash and to investigate the effect of borax usage as additive in geopolymer mixture on its setting time. Effect of the use of borax on the setting time and compressive strength of geopolymer will be discussed.

\section{Experimental Method}

Material. High calcium and low calcium fly ash were obtained from a power plant in Paiton, East Java, Indonesia. Each fly ash was coded in relation with their measured $\mathrm{pH}$ value [3]. Physical properties of fly ash, i.e. particle size distribution, specific gravity and particle shape, were evaluated. In addition to the physical examination, x-ray fluorescence (XRF) analysis was also performed to examine the chemical content of fly ash. Chemical compound and physical properties of the fly ash can be seen in Table 1 .

Table 1. Fly ash chemical and physical properties

\begin{tabular}{ccc}
\hline Oxide (\%, by mass) & Fly ash Y11.2 & Fly ash Y9.8 \\
\hline $\mathrm{SiO}_{2}$ & 39.78 & 51.12 \\
$\mathrm{Al}_{2} \mathrm{O}_{3}$ & 17.87 & 18.90 \\
$\mathrm{Fe}_{2} \mathrm{O}_{3}$ & 15.00 & 17.71 \\
$\mathrm{CaO}$ & 15.47 & 5.54 \\
$\mathrm{~K}_{2} \mathrm{O}$ & 1.32 & 0.82 \\
$\mathrm{MgO}$ & 6.45 & 3.17 \\
$\mathrm{SO}_{3}$ & 1.32 & 0.47 \\
$\mathrm{MnO}_{2}$ & 0.18 & 0.33 \\
$\mathrm{LOI}$ & 0.49 & 6.96 \\
\hline $\mathrm{SSA}\left(\mathrm{m}^{2} / \mathrm{kg}\right)$ & 2618 & 1785 \\
$\mathrm{D}_{\mathrm{v}}(50)(\mu \mathrm{m})$ & 6.98 & 10.30 \\
$\mathrm{D}_{\mathrm{v}}(90)(\mu \mathrm{m})$ & 60.80 & 84.30 \\
$\mathrm{Specific}_{\mathrm{gravity}}$ & 2.63 & 2.36 \\
\hline
\end{tabular}

ASTM Standard C618 [15] classifies fly ash as pozzolanic material based on the total content of the main chemical compounds of $\mathrm{SiO}_{2}, \mathrm{Fe}_{2} \mathrm{O}_{3}$ and $\mathrm{Al}_{2} \mathrm{O}_{3}$ to be more than $70 \%$. Both fly ash samples used in this study satisfy the standard. Based on the $\mathrm{CaO}$ content, fly ash $\mathrm{Y} 11.2$ can be classified as type C (high calcium) fly ash, while fly ash Y9.8 is classified as type F (low calcium) fly ash.

Borax was obtained in anhydrous form from local chemical store. Sand from Lumajang, East Java, with fineness modulus of 2.52 was used for making the geopolymer mixture. Alkaline solution was prepared from a combination of sodium hydroxide $(\mathrm{NaOH})$ and sodium silicate solution.

Mixture proportion and sample preparation. Experimental study was conducted on geopolymer mortar to measure the compressive strength and on geopolymer paste to measure the setting time. Samples were prepared with alkaline solution to fly ash ratio of 0.25 and sand to fly ash ratio of 2.0, by mass. Sodium hydroxide solid was dissolved in water one day prior mixing. 
Borax was dissolved into the sodium hydroxide solution before mixing it with sodium silicate solution. The ratio of alkaline solution, which defined as the ratio of sodium silicate liquid to sodium hydroxide solid, by mass, was set at 2.0. The addition of borax into the geopolymer mixture was varied from $0,1,2,3,5$ and $7 \%$, by mass of fly ash. Fine aggregate and fly ash was mixed thoroughly before mixing with the alkaline activator and borax.

Compressive strength and setting time test. Fresh geopolymer mortar was cast in $50 \mathrm{~mm}$ cube mould to prepare for compressive testing. After casting, plastic sheet was wrapped to the mould and cured at $60^{\circ} \mathrm{C}$ for 24 hours. After curing, samples were demolded and stored at room temperature until the day of testing. Compressive strength tests were conducted on mortar cubes aged 7 days. Three specimens were made for each variation. Setting time of the geopolymer paste was measured by using Vicat needle apparatus [16]. The initial setting time was determined from needle penetration of $25 \mathrm{~mm}$, while final set was noted when no penetration was observed any longer. Setting time of the geopolymer paste was measured in the laboratory condition with no heat curing.

\section{Results and Discussions}

Flash setting. The occurrence of flash setting was observed by the rapid hardening of the geopolymer paste. Black [10] noted that there might be two conditions for the flash setting to occur, i.e. when the $\mathrm{NaOH}$ concentration is very high and when high calcium fly ash is used. Authors' previous experience with the geopolymer flash setting mostly can be attributed to the high calcium content in the fly ash. However, there are other factors that could lead to flash setting such as the reactivity of fly ash related to its particle size, casting temperature, and high volume mixing. Lower liquid content in the geopolymer mixture could also causing rapid stiffening in the mixture. Sodium silicate to sodium hydroxide ratio has contributing effect. Higher silicate ratio accelerates the polymerization reaction, as shown by the increase of compressive strength, and at the same time also accelerating the early stiffening of the matrix.

In most cases, flash setting can be detected easily, as the fresh mixture would be already too stiff to be poured into the mould only after a few minutes. Figure 1 shows some defective specimens with big entrapped air when flash setting occurs. The fresh geopolymer was poured into the mould in one layer and compacted on the vibrator table. It was realized that the vibration cannot expel the entrapped air because the matrix was already very stiff, even when the vibration was carried out immediately after pouring. Evaluating the specimens' density need to be performed to detect the internal entrapped void.

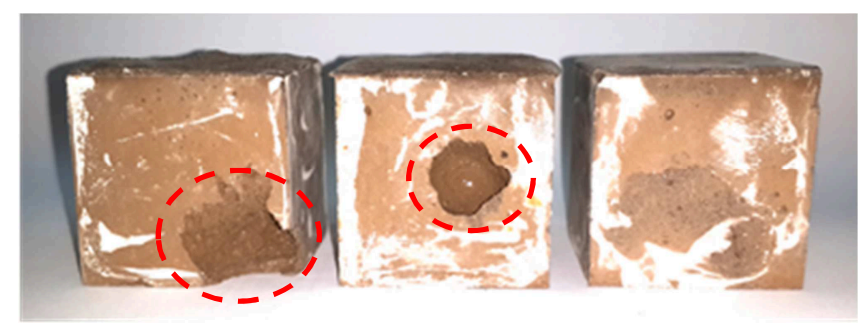

Figure 1. Flash setting observed after opening the mould.

Setting time. Setting time of the geopolymer paste was measured using Vicat needle apparatus. Geopolymer paste was prepared with the mixture proportion exactly the same as the one for making the geopolymer mortar, with the removal of the sand content. Therefore the geopolymer paste is slightly soggier. Figure 2(a) and (b) show the graph of Vicat needle penetration into the paste with time for fly ash Y11.2 and Y9.8, respectively. Control mixture without borax shows fast setting time, especially on geopolymer paste with fly ash Y11.2. Figure 2(a) indicates some penetration resistance occurs only within 5 minutes. The addition of borax shows the increase in the setting time of geopolymer paste, compared to the one of the control mixture. Borax addition is shown to cause similar prolong initial setting time, irrespective of the borax content. However, the trend is different with the final setting time. Borax addition of $5 \%$ shows a different setting time behavior. 
The slope of penetration was reduced with the increase of time. This shown that the early reaction rate of the geopolymer was retarded by the addition of borax. Kusbiantoro et al. confirmed that the hardening behavior of geopolymer paste was quite abrupt [13], similar to the control mixture in this research. Adding sucrose only shifted the setting time, without altering the abruptness of setting. The decrease of slope with the addition of borax in the geopolymer mixture suggests that there could be a change on the rate of the geopolymerization process. Fly ash with lower calcium content causes slower setting time, as shown by Figure 2(b).
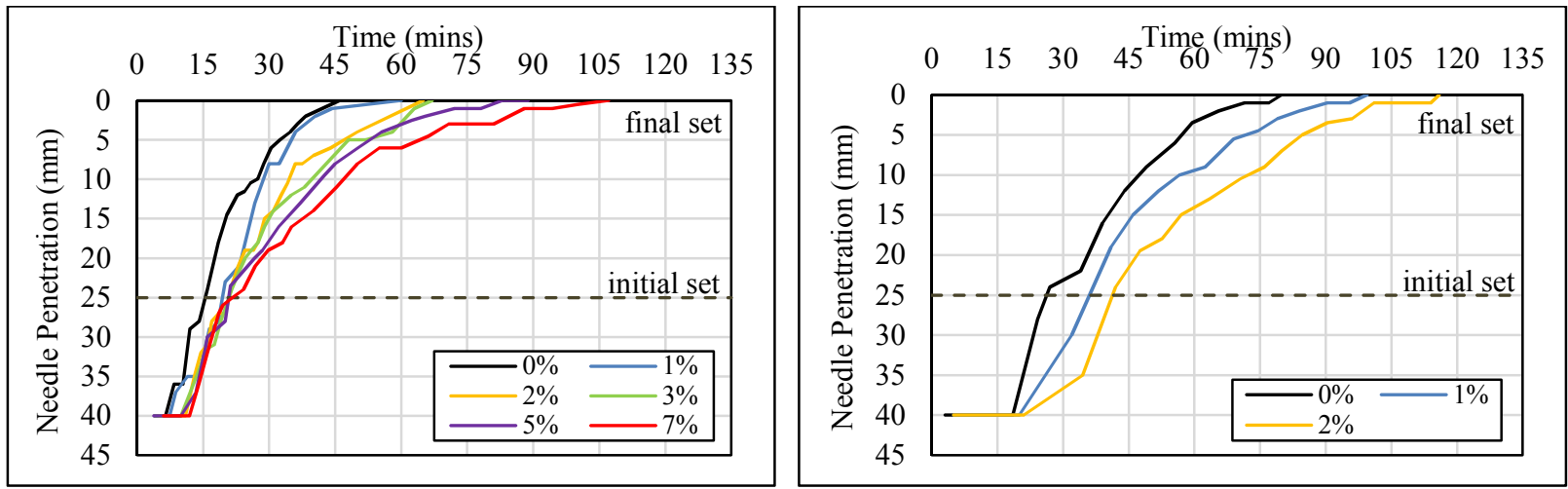

Figure 2. Setting time measured by Vicat needle penetration for geopolymer paste with: (a) Fly ash Y11.2 and (b) Fly ash Y9.8

Compressive strength. The compressive strength of geopolymer mortar with fly ash Y11.2 and Y9.8 is shown in Figure 3. From the control sample without borax, it was shown that geopolymer mortar with fly ash Y11.2 has higher compressive strength of $85.33 \mathrm{MPa}$, compared to the one with fly ash Y9.8 (73.07 MPa). Higher compressive strength due to the use of fly ash with higher $\mathrm{CaO}$ content could be attributed to the presence of hydration reaction, beside the geopolymerization reaction. With the addition of 1 to $5 \%$ borax, the compressive strength is shown to be slightly increased. The highest compressive strength of $90.53 \mathrm{MPa}$ is observed with the addition of $1 \%$ borax. At $7 \%$ borax addition, the compressive strength was slightly reduced to $82.80 \mathrm{MPa}$.

For geopolymer mortar with fly ash Y9.8, the addition of borax was performed at 0,1 and $2 \%$ by mass of fly ash. It serves as a control mixture as well. Figure 3 shows that the addition of borax of $2 \%$, increases the compressive strength from $73.07 \mathrm{MPa}$ to $88.67 \mathrm{MPa}$. This indicates that borax addition has also positive effect in increasing the compressive strength, in addition to delaying the setting time of the geopolymer.

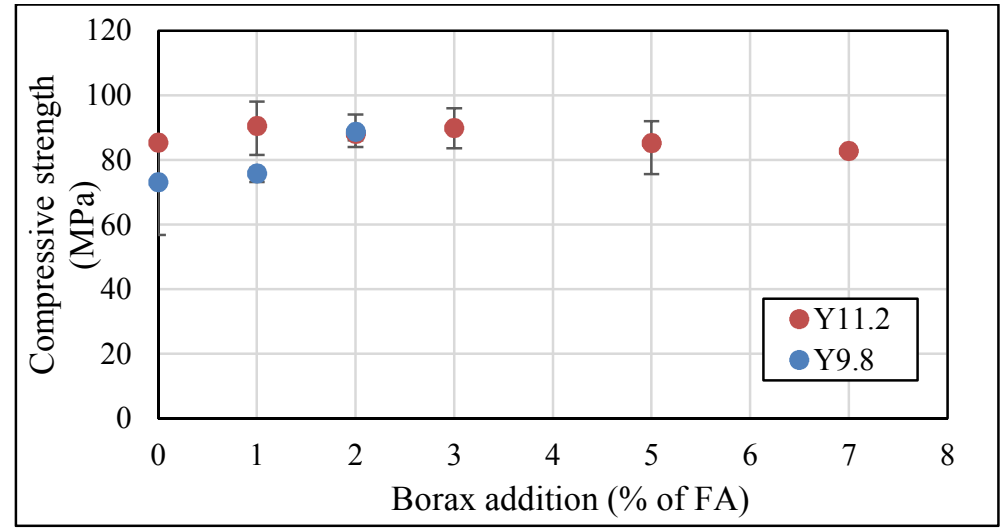

Figure 3. Compressive strength of geopolymer mortar on $7^{\text {th }}$ day with addition of borax.

\section{Conclusions}

- The pH level of fly ash can be used as one indicator to detect the possible occurrence of flash setting of fly ash-based geopolymer, especially the one using high calcium fly ash. The occurrence of flash setting in geopolymer can hinder its application in large scale or volume. 
- The addition of borax in the mixture can prolong the setting time of the fly ash-based geopolymer, especially on those using high calcium fly ash.

- The compressive strength of geopolymer is slightly increased with the addition of borax.

- Low calcium fly ash-based geopolymer with no tendency of flash setting can also be benefitted from the addition of borax. The addition of borax at 1 to $3 \%$ by mass of low calcium fly ash improves the uniformity of the mixture and hence increases its compressive strength.

\section{Acknowledgements}

The authors gratefully acknowledge The Ministry of Research, Technology and Higher Education, Indonesia, who provided the research grant.

\section{Reference}

[1] D. Cross, J. Stephen, and J. Vollmer, "Structural application of 100 percent fly ash concrete", 2005 WOCA, Lexington, USA, 6 April (2005).

[2] S. Tsimas and A. Moutsatsou-Tsima, "High-calcium fly ash as the fourth constituent in concrete: problems, solutions and perspectives". Cem. \& Concrete Composites, 27(2), 231-237. (2005).

[3] Antoni, R. Gunawan and D. Hardjito, "Rapid Indicators in Detecting Variation of Fly Ash for Making HVFA Concrete" Appl. Mech. Mater. Vol. 815 pp 153-157 (2015).

[4] P. Chindaprasirt, T. Chareerat, and V. Sirivivatnanon, "Workability and strength of coarse high calcium fly ash geopolymer". Cement and Concrete Composites, 29(3), 224-229. (2007).

[5] X. Guo, H. Shi, and W.A. Dick, "Compressive strength and microstructural characteristics of class C fly ash geopolymer". Cement and Concrete Composites, 32(2), 142-147. (2010).

[6] P. Topark-Ngarm, P. Chindaprasirt, and V. Sata, "Setting Time, Strength, and Bond of HighCalcium Fly Ash Geopolymer Concrete". Journal of Materials in Civil Engineering (2014).

[7] S. Pangdaeng, T. Phoo-ngernkham, V. Sata, and P. Chindaprasirt, "Influence of curing conditions on properties of high calcium fly ash geopolymer containing Portland cement as additive". Materials \& Design, 53, 269-274. (2014).

[8] D. Hardjito, C.C. Cheak, and C.H.L. Ing, "Strength and setting times of low calcium fly ashbased geopolymer mortar", Mod. Appl. Sci. Vol 2, No 4, (2008).

[9] J. Tailby and K.J.D. MacKenzie, "Structure and mechanical properties of aluminosilicate geopolymer composites with Portland cement and its constituent minerals", Cem. \& Con. Res. Vol. 40 pp 787-794, (2010).

[10]J.R. Black, "Mix design process for alkaline-activated class F fly ash geopolymer concrete", Final project report, University of New South Wales, Australia (2012).

[11]H.W. Nugteren, V.C.L. Butselaar-Orthilieb, M. Izquierdo, G.J. Witkamp, and M.T. Kreutzer, "High strength geopolymer from fractionated and pulverized fly ash", 2009 WOCA. Lexington, USA, May (2009).

[12]J. Davidovits, Geopolymer chemistry and applications, $2^{\text {nd }}$ ed. Saint-Quentin, France: Institute Géopolymère, (2008).

[13]A. Kusbiantoro, M.S. Ibrahim, K. Muthusamy, and A. Alias, "Development of sucrose and citric acid as the natural based admixture for fly ash based geopolymer", Proc. Env. Sci. Vol 17 pp 596-602, (2013).

[14]A. Nazari, A. Maghsoudpour, and J.G. Sanjayan, "Flexural strength of plain and fiber reinforced boroaluminosilicate geopolymer", Const. \& Build. Materials.Vol. 76 pp 207-213, (2015).

[15]ASTM C618-08, Standard Specification for Coal Fly Ash and Raw or Calcined Natural Pozzolan for Use in Concrete, ASTM International, West Conshohocken, PA, (2008)

[16]ASTM C191-04, Standard Test Method for Time of Setting of Hydraulic Cement by Vicat Needle, ASTM International, West Conshohocken, PA, (2004) 